\title{
Predicting Reference Evaporation for the Ethiopian Highlands
}

\author{
Anwar A. Adem ${ }^{1,2}{ }^{*}$, Dessalew W. Aynalem ${ }^{1}$, Seifu A. Tilahun ${ }^{1}$, Tammo S. Steenhuis ${ }^{1,3}$ \\ ${ }^{1}$ Faculty of Civil and Water Resources Engineering, Bahir Dar University, Bahir Dar, Ethiopia \\ ${ }^{2}$ Department of Natural Resource Management, Bahir Dar University, Bahir Dar, Ethiopia \\ ${ }^{3}$ Department of Biological and Environmental Engineering, Cornell University, Ithaca, NY, USA \\ Email: ^anwarasefa@gmail.com, workudessu@mail.com, satadm86@mail.com, tss1@cornell.edu
}

How to cite this paper: Adem, A.A., Aynalem, D.W., Tilahun, S.A. and Steenhuis, T.S. (2017) Predicting Reference Evaporation for the Ethiopian Highlands. Journal of Water Resource and Protection, 9, 1244-1269. https://doi.org/10.4236/jwarp.2017.911081

Received: September 21, 2017

Accepted: October 28, 2017

Published: October 31, 2017

Copyright (C) 2017 by authors and Scientific Research Publishing Inc. This work is licensed under the Creative Commons Attribution International License (CC BY 4.0).

http://creativecommons.org/licenses/by/4.0/

\section{(c) (i) Open Access}

\begin{abstract}
Water is likely the most limiting factor in increasing agricultural production in large parts of Africa. Reference evaporation $\left(\mathrm{ET}_{0}\right)$ is a key hydrological parameter to use efficiently the scarce supply. Several methods are available for predicting reference evaporation, but the accuracy of any of the methods has not been established for the Ethiopian highlands. The objective of this study is, therefore, to select the best methods for calculating the reference evaporation $\mathrm{ET}_{0}$. For the section, meteorological data of the Bahir Dar station were used, because all data needed for this study including the Class A pan Evaporation were recorded on a daily basis. Pan evaporation was considered as the best estimator of the reference evaporation. The results showed that the FAOPenman Monteith (using solar radiation, wind speed, temperature and relative humidity) and Enku method (using only maximum daily temperatures) have acceptable daily $\mathrm{ET}_{0}$ ranges and predicted to Class A pan evaporation with correlation coefficients greater than $90 \%$ in a monthly basis. Next best was the Thornthwaite's method with correlation coefficient of $89 \%$ with pan evaporation. Piche methods performed relatively well with correlation coefficient of greater than $70 \%$. Blaney-Criddle, Priestley \& Taylor, and Hargreaves performed the poorest in predicting pan evaporation. These methods should be recalibrated for local condition and therefore not recommended for use in the Ethiopian highlands. In summary, the FAO-Penman Monteith is recommended for locations where the input data are available; otherwise, the Enku method using maximum daily temperature is best for estimating the reference evaporation.
\end{abstract}

\section{Keywords}

Pan, Piche, Africa, Potential Evaporation, FAO-56 


\section{Introduction}

Throughout Africa, good quality water is being recognized as a finite resource that is in short supply-limiting development in many cases [1]. The Blue Nile basin is one of areas in Africa of extreme water scarcity: nearly 150 million people are dependent on the Blue Nile river with a discharge of less than 85 billion $\mathrm{m}^{3}$ [2] [3]. Understandably, careful assessment of the use of water needs to be made because in the future, it will be increasingly important to match the supply (i.e., excess rainfall) in the Ethiopian highlands with the demand by irrigation systems, industry, and population in the basin. Estimating reference evaporation provides fundamental information on water abstraction in the highlands and downstream when used in combination with crop coefficients [4].

Estimating reference evaporation $\left(\mathrm{ET}_{0}\right)$ has taken many forms ranging from direct measurement to indirect methods employing meteorological measurements. One of the direct measurements is the Class A evaporation pan. The pan evaporation can be related to reference evaporation with coefficients developed by $\mathrm{Pe}$ reira et al. [5] and Allen et al. [6]. The disadvantage of Class A evaporation pans are only their availability at a few locations in developing countries. Indirect methods are, therefore, a good alternative and range from locally developed, empirical relationships to physically based energy- and mass-transfer models [7]. The meteorological data required vary with the type of indirect methods. The Penman and Priestley and Taylor methods require most meteorological data and the Penman is generally considered as the most accurate one [8] [9] [10] [11] [12], but as for the Class A pan data, the required data is only collected at few meteorological stations. Thornthwaite Mather, which is used frequently in Ethiopia, needs fewer climatic data (temperature and sunshine hour). The Hargraves, Blaney-Criddle, and Enku (locally developed) need only temperature to estimate the reference evaporation. Finally, methods that use the measurements of a Piche evaporimeter to calculate the reference evaporation were developed by [13] and [14].

Reference evaporation is defined by Meyer [4] as the rate of evaporation from a hypothetical crop with an assumed crop height of $12 \mathrm{~cm}$ and fixed canopy resistance of $70 \mathrm{~s} \mathrm{~m}^{-1}$ and an albedo of 0.23 and would give the same evaporation rate as envisioned by Smith et al. [9] of an extensive surface of green actively growing completely shading the ground and not short of water. It is of course difficult to replicate the conditions that define the reference evaporation. Several methods have been used to validate the direct and indirect methods. In the literature, these validation methods are divided in four categories. The first category uses the evaporation measured with Class A pan [15] [16] [17]. Other studies employ the $\mathrm{ET}_{0}$ of FAO-Penman Monteith for validation [7] [10] [11] [18] [19] [20] [21]. Limited experimental studies have used the $\mathrm{ET}_{0}$ calculated from Piche data for validation [19]. The final method used for validation of calculated reference evaporation are lysimeters [22] [23] [24] [25] but these are expensive to construct and operate and therefore not available in most developing countries. 
Agronomists and hydrologists have little guidance [15] [26] to choose among the many available methods to estimate reference evaporation in the Ethiopian highlands where the density of weather station is low [27] [28] and often only measure temperature and precipitation. The objective of this study is, therefore, to select the most accurate method for estimating reference evaporation for the Ethiopian highlands. The Bahir Dar meteorological station was chosen for this study because as the only station in the Ethiopian highlands, all the meteorological variables were measured required for calculating the reference evaporation for all the methods considered. The data recorded on a daily basis included maximum and minimum temperature, relative humidity, wind speed, and sunshine hours and evaporation measured with the Piche and Class A pan.

\section{Material and Methods}

\subsection{Site Description and Data Set}

The Ethiopian highlands is the region in Ethiopia above $1500 \mathrm{~m}$ and covers a total area of 537,000 $\mathrm{km}^{2}$ (43\% of Ethiopia) [29] [30]. It constitutes more than half of all the highland areas of Africa [31]. Most of the area of the highlands is cultivated land and land degradation is a major threat. One of the main rivers is the Blue Nile with a watershed of $180,000 \mathrm{~km}^{2}$. It has a monsoonal climate with rainfall varying between 800 and $3000 \mathrm{~mm}$ per year and evapotranspiration between 1400 and 1681 per year [32]. The major rain phase for the highlands of Ethiopia is between June and September.

One of the difficulties in the Ethiopian highlands is that pan evaporation data is measured only at the Bahir Dar Station for long period. It is located $2.2 \mathrm{~km}$ from Lake with latitude of $11^{\circ} 35^{\prime} 59^{\prime \prime}$ and longitude of $37^{\circ} 21^{\prime} 36^{\prime \prime}$. The elevation is $1805 \mathrm{~m}$ (Figure S1 in the Supplementary Material). The station has more than 30 years of data but Pan Evaporation started only in 2005 (Table S1 in the Supplementary Material list the collected data). Daily maximum and minimum temperature, relative humidity, sunshine hour, wind speed at 2 meter, pan and Piche evaporation data were obtained for the 11 years from 2005 to 2015 from Bahir Dar Meteorology Directorate.

\subsection{Reference Evaporation: Description of the Selected Methods}

FAO-Penman Monteith, Priestley \& Taylor, Hargraves, Thonthwaite, Blaney-Criddle, Enku, Pan-Allen, Pan-Pereira, Piche-Stanhill and Piche-Adam \& Ahmed methods were selected. The first four are used locally by experts and by researchers for hydrological modeling and in computations of irrigation water requirement. Piche-Stanhill and Piche-Adam \& Ahmed methods were included because of availability Piche readings in several weather stations in the Ethiopian highlands. Pan-Allen and Pan-Pereira methods were used for validation of the rest of the empirical models. Since the Penman has not been validated for the Ethiopian highlands, the Class A pan data using coefficients proposed by Pereira et al. [5] and Allen et al. [6] are used as the direct measure of reference evaporation against which the calcu- 
lated values are compared.

\section{1) FAO-Penman Monteith Method (FAO-PEN)}

FAO-Penman Monteith method computes reference evapotranspiration $\left(\mathrm{ET}_{0}\right)$ from meteorological data. It has been recommended as the standard method for computation of the reference evapotranspiration. The method considers all parameters that govern energy exchange and corresponding latent heat flux and requires air temperature, relative humidity, sunshine intensity/hour, wind speed data and elevation as input parameters.

The modified Penman-Monteith equation can be written as [6]:

$$
E T_{0}=\frac{0.408 \Delta(R n-G)+\gamma \frac{900}{T+273} u_{2}\left(e_{s}-e_{a}\right)}{\Delta+\gamma\left(1+0.34 u_{2}\right)}
$$

where $E T_{0}$ reference evapotranspiration $\left[\mathrm{mm} \mathrm{day}^{-1}\right], R_{n}$ net radiation at the crop surface $\left[\mathrm{MJ} \mathrm{m}^{-2} \mathrm{day}^{-1}\right], G$ soil heat flux density $\left[\mathrm{MJ} \mathrm{m}^{-2}\right.$ day $\left.^{-1}\right], T$ mean daily air temperature at $2 \mathrm{~m}$ height $\left[{ }^{\circ} \mathrm{C}\right], u_{2}$ wind speed at $2 \mathrm{~m}$ height $\left[\mathrm{m} \mathrm{s}^{-1}\right], e_{s}$ saturation vapor pressure $[\mathrm{kPa}], e_{a}$ actual vapor pressure $[\mathrm{kPa}], e_{s}-e_{a}$ saturation vapor pressure deficit $[\mathrm{kPa}], \Delta$ slope vapor pressure curve $\left[\mathrm{kPa}{ }^{\circ} \mathrm{C}^{-1}\right], \quad \gamma$ psychrometric constant $\left[\mathrm{kPa}^{\circ} \mathrm{C}^{-1}\right]$. Further details how these parameters are calculated are given in the Supplementary Material Section.

2) Priestley \& Taylor Method (PT)

The Priestley \& Taylor form of the equation is [15] [33] [34]:

$$
E T_{0}=\frac{\alpha \frac{\Delta}{\Delta+\gamma}\left(R_{n}-G\right)}{\lambda}
$$

where;

$$
\alpha=1+\frac{\gamma}{\Delta+\gamma} * \frac{r_{s}}{r_{a}}
$$

where; $r_{s}$ is surface resistance $\left[\mathrm{s} \mathrm{m}^{-1}\right]$ which is $70 \mathrm{~s} \mathrm{~m}^{-1}$ for the grass reference surface, $r_{a}$ is aerodynamic resistance which helps to determine the transfer of heat and water vapor from the evaporating surface into the air above the canopy. The aerodynamic resistance $r_{a}\left[\mathrm{~s} \mathrm{~m}^{-1}\right]$ for the grass reference surface becomes:

$$
r_{a}=\frac{208}{u_{2}}
$$

where $u_{2}$ is the wind speed $\left[\mathrm{m} \mathrm{s}^{-1}\right.$ ] at $2 \mathrm{~m}$.

3) Hargraves Method ( $H A R)$

This method requires daily maximum and minimum air temperature, and extraterrestrial solar radiation, which is computed from the latitude of the study site. The Hargreaves and Samani [35] equation is defined as follows:

$$
E T_{0}=0.0023\left(T_{\max }-T_{\text {min }}\right)^{0.5}\left(T_{\text {mean }}+17.8\right) R_{a}
$$

where $T_{\min }$ daily minimum temperature $\left[{ }^{\circ} \mathrm{C}\right], T_{\max }$ saturation vapor pressure at daily maximum temperature and $R_{a}$ extraterrestrial radiation $\left[\mathrm{MJ} \mathrm{m}^{-2}\right.$ day $^{-1}$. 


\section{4) Thornthwaite Method ( $\mathrm{TH})$}

This formula is based mainly on temperature with an adjustment factor for the number of daylight hours. The potential evapotranspiration, calculated on a monthly basis, is [36]:

$$
P E^{\prime}=16\left(\frac{10 \overline{T_{m}}}{I}\right)^{a}
$$

where the subscript $m$ indicates the months $1,2,3, \ldots, 12, T_{m}$ is the monthly mean temperature $\left({ }^{\circ} \mathrm{C}\right), I$ is the heat index for the year, given by:

$$
I=\sum i_{m}=\sum\left(\overline{\frac{T_{m}}{5}}\right)^{1.5}
$$

where, $i_{m}$ is monthly values of heat index and $a$ is empirical coefficient defined as

$$
a=6.7 \times 10^{-7} I^{3}-7.7 \times 10^{-5} \times I^{2}+1.8 \times 10^{-2}+0.49
$$

Therefore,

$$
E T_{0}=P E^{\prime}\left(\frac{d}{12}\right)\left(\frac{N_{m}}{30}\right)
$$

where, $N_{m}$ is the monthly adjustment factor related to hours of daylight, $E T_{0}$ reference evaporation [mm/day], $d$ duration of daylight [hr].

5) Blaney-Criddle Method ( $B C$ )

The Blaney-Criddle equation has been used to calculate the reference crop evapotranspiration $E T_{0}$ when pan evaporation is not available. It can be expressed as [37]

$$
E T_{0}=p\left(0.46 T_{\text {mean }}+8\right)
$$

where $E T_{0}$ is reference crop evapotranspiration (mm/day) averaged over the month $T_{\text {mean }}=$ mean daily temperature $\left({ }^{\circ} \mathrm{C}\right)$, and $\mathrm{p}$ is mean daily percentage of annual daytime hours and varies between 0.26 and 0.29 for Bahir Dar.

6) Enku's Simple Temperature Method (ENKU)

The new simple empirical temperature method, which was named by "Enku's simple temperature method", was developed [19] and tested in Ethiopia with Penman Montieth reference Evaporation and the Piche Evaporimeter. The equation is:

$$
E T_{0}=\frac{\left(T_{\max }\right)^{n}}{k}
$$

where $E T_{0}$ is the reference evapotranspiration $\left(\mathrm{mm} \mathrm{day}^{-1}\right) ; n=2.5$ for the Lake Tana area; $k$ is the coefficient, which is calibrated for local conditions ranging from about 600 for lower mean annual maximum temperature areas to 1300 for higher mean annual maximum temperature areas. The coefficient, $k$, was found by Enku and Melesse [19] as $k=48 * T_{m m}-330$ for combined wet and dry conditions or $k=73 * T_{m m}-1015$ for the dry phase, and $k=38 * T_{m m}-63$ for the rain phase, where $T_{m m}(\mathrm{C})$ is the long term daily mean maximum temperature for the seasons under consideration. 


\section{7) Pan Methods}

The evaporation rate from Class A Pans filled with water is easily obtained. In the absence of rain, the amount of water evaporated during a period $(\mathrm{mm} /$ day) corresponds with the decrease in water depth. Pans provide a measurement of the integrated effect of radiation, wind, temperature and humidity on the evaporation from an open water surface [6].

There are two types of Pan Models to estimate reference evaporation.

a) Pereira Model $(P A N-P)$

According to Pereira et al. [5], the reference evaporation, $E T_{0}$ from pan data calculated with:

$$
E T_{0}=E_{p a n} \cdot K_{1}
$$

where; $E T_{0}$ reference evapotranspiration [mm/day], $K_{1}$ pan coefficients [-], $E_{P_{a n}}$ Class A pan evaporation [mm/day].

$$
K_{1}=\frac{0.85(\Delta+\gamma)}{\left[\Delta+\gamma\left(1+0.33 u_{2}\right)\right]}
$$

b) Allen Model $(P A N-A)$

As Allen et al. [6], $E T_{0}$ from pan data calculated with:

$$
E T_{0}=E_{p a n} \cdot K_{2}
$$

The pan coefficient $K_{2}$ for Class A pan with green fetch can be found as [6]:

$$
\begin{aligned}
K_{2}= & 0.108-0.0286 u_{2}+0.0422 \ln (F)+0.1434 \ln (R H) \\
& -0.000631[\ln (F)]^{2} \ln (R H)
\end{aligned}
$$

where $F$ is fetch or distance of the reference grass $(\mathrm{m})$ and $R H$ is the relative humidity in percent.

8) Piche Methods

The Piche evaporimeter is a type of atmometer used to measure the rate of evaporation from a wet disc of absorbent paper. It is used mainly in hot, dry climates where water loss through evaporation must be observed regularly. Since the results are dependent on wind speed past the disc, as well as the wet bulb saturation deficit, it is almost essential to expose the evaporimeter inside a meteorological screen [14] [38] [39].

There are two types of Piche models used in this study to estimate evapotranspiration.

a) Stanhill Method (PI-S)

Stanhill [13] suggested that it may be possible to estimate the second term in Penman's equation from available sheltered Piche evaporation data $\left(E_{p i}\right)$ as follows.

$$
E T_{0}=\frac{\Delta R_{n}}{\Delta+\gamma}+a E_{p i}+b
$$

where $a$ slope and $b$ is intercept of a linear relation with the aerodynamic term of Penman equation: 


$$
a E_{p i}+b=\frac{\gamma}{\Delta+\gamma} E_{a}
$$

where;

$$
E_{a}=f(u)\left(e_{s}-e_{a}\right)
$$

where $f(u)$ is an aerodynamic wind function and $\left(e_{s}-e_{a}\right)$ is the difference between saturated vapour pressure and actual vapour pressure in $\mathrm{hPa}$, evaluated at mean air temperature and at $2 \mathrm{~m}$ above the ground or water surface.

The equivalent to the wind function of Penman [40] is

$$
f(u)=0.263\left(a_{u}+b_{u} a\right)
$$

where $u$ is the wind speed in $\mathrm{m} \mathrm{s}^{-1}$ at $2 \mathrm{~m}$ elevation, and $a$, and $b$, are empirical coefficients. Penman [40], Penman [41] suggested using values equivalent to 1 and 0.537 for $a$, and $b$, respectively for a short grass cover when $u$ is measured in $\mathrm{m} \mathrm{s}^{-1}$.

b) Adam \& Ahmed Method (PI-ADAH)

Adam and Ahmed [14] showed that the ratio of Penman estimated and Piche evaporation have relation with relative humidity exponentially. That is:

$$
\frac{E T_{0}}{E_{P i}}=a e^{b R H}
$$

where $a$ and $b$ are constants that can be find from the exponential relation and the $R H$ humidity in percent

\subsection{Methods of Data Analysis}

The collected meteorological data for Bahir Dar (2005-2015) was of good quality with less than $5 \%$ of missing data. A simple arithmetic mean was used to determine the missing data. Reference evaporation was computed at daily and monthly time step using the 10 methods listed above after data preparation.

In addition, we compared the calculated reference evaporation with the ten methods using three techniques: visual inspection, descriptive statistics and statistical methods to test methods of efficiency and their standard error. The visual inspection of plotted $\mathrm{ET}_{0}$ prediction methods reveals whether the calculated reference evaporation is in agreement with either other methods or an outlier. Descriptive statistics like maximum, absolute minimum, median value, total range of values, standard deviation, and coefficient of variation were used to compare the $\mathrm{ET}_{0}$ prediction methods.

In this study, every single model was correlated with the pan $E T_{0}$ s to assess the model performances and standard error. Pearson's correlation and root mean square error (RMSE) equations were used for this purpose.

The formula for the Pearson product moment correlation coefficient, $r$, is:

$$
r=\frac{\sum(x-\bar{x})(y-\bar{y})}{\sqrt{\sum(x-\bar{x})^{2} \sum(y-\bar{y})^{2}}}
$$

The equation for the standard error of the predicted $y$ is: 


$$
\sqrt{\frac{1}{n-2}\left[\sum(y-\bar{y})^{2}-\frac{\left[\sum(x-\bar{x})(y-\bar{y})\right]^{2}}{\sum(x-\bar{x})^{2}}\right]}
$$

where $\bar{x}$ and $\bar{y}$ are the sample means.

A sensitivity analysis was carried out to evaluate the percentage response of calculated $E T_{0}$ to selected weather variables. Changes of model outputs and their variability induced by change in weather variables were evaluated. The change in variables was analyzed for values $25 \%$ above and $25 \%$ below the mean value.

Mann Kendall trend test was used to indicate whether there are trends in the $E T_{0}$ computed using the ten methods. Non-parametric Mann Kendall Trend Test is useful to examine the temporal variation trend. It is based on the significance of differences, not directly on the random values. Therefore the trend that's been determined is less affected by outliers [42]. The nonparametric Mann-Kendall trend test has been applied in many studies to identify whether monotonic trends exist in hydro-meteorological data such as temperature, rainfall and stream flow [43]. The Mann Kendall Trend Test, $S$ is calculated by using the equation below [44] [45].

$$
S=\sum_{i=1}^{N-1} \sum_{j=i+1}^{N} \operatorname{sgn}\left(x_{i}-x_{j}\right), \operatorname{sgn}\left(x_{i}-x_{j}\right)=\left\{\begin{array}{l}
+1 \rightarrow x_{i}-x_{j}>0 \\
0 \rightarrow x_{i}-x_{j}=0 \\
-1 \rightarrow x_{i}-x_{j}<0
\end{array}\right.
$$

where $x_{j}$ and $x_{i}$ are the sequential data value and $j$ greater than $i, N$ is the length of the data set.

As indicated in Mann [44] and Kendall and Stuart [46], when $N \geq 8$, the distribution of $S$ approaches the Gaussian form with mean $E(S)=0$ and variance $\operatorname{Var}(S)$ given by:

$$
\operatorname{Var}(S)=\frac{N(N-1)(2 N+5)-\sum_{m=1}^{N} t_{i}(m-1)(2 m+5) m}{18}
$$

where: $t_{i}$ is the number of ties of length $m$.

The statistic $S$ is then standardized ( $Z$ ), and its significance can be estimated from the normal cumulative distribution function.

$$
Z=\left\{\begin{array}{l}
\frac{S-1}{\sqrt{V(s)}} \rightarrow S>0 \\
0 \rightarrow S=0 \\
\frac{S+1}{\sqrt{V(s)}} \rightarrow S<0
\end{array}\right.
$$

The positive $Z$ value indicates an increasing trend while a negative $Z$ value indicates a decreasing trend. When testing two sided trends at a selected level of significance a, the null hypothesis $\left(\mathrm{H}_{0}\right)$ of no trend is rejected if the absolute value of $Z$ is greater than $Z_{a / 2}$ where a represents the chosen significance level (5\% with $\left.Z_{0.025}=1.96\right)$. 


\section{Results}

\section{Reference Evaporation: Calculated Values}

The reference evaporation, $\mathrm{ET}_{0}$, was calculated for a daily and monthly time step. In Figure 1, as an example, the $2005 \mathrm{ET}_{0}$ for the ten methods are depicted. Values calculated for the other years are shown in tabular form in Table S2 in the supplementary material. The minimum reference evaporation calculated was 0 $\mathrm{mm}$ /day (Thornthwaite) and $16.3 \mathrm{~mm} /$ day (Hargraves and Priestley-Taylor). Blaney-Criddle has the smallest range (the difference in daily maximum and minimum values) while Priestley-Taylor has the largest range of values. The FAO-Penman and Enku methods have acceptable daily $\mathrm{ET}_{0}$ ranges between 1.5 and $6.5 \mathrm{~mm} /$ day [6] [15] [47].

Seasonally, the reference evaporation of each of the methods is greater during the dry phase from February to May when the temperature is high and there are few clouds than during the rain phase from June to September when it is cloudy and less warm (Figure 1, Figure 2). In addition, the reference evaporation decreases in December and January for some of the methods (Figure 1, Figure 2) due to cloudiness caused by of easterlies carrying moisture from Arabian Sea.

In equatorial countries like Ethiopia, the difference in sunshine duration between months is minimal and the difference in $\mathrm{ET}_{0}$ is due to cloud cover mainly and temperature and relatively humidity secondly. This is different from temperate climates where the day length is the primary factor that determines the magnitude of the reference evaporation during the year.

The methods by Enku, Class A pan (both), FAO-Pennman Monteith and the Adam and Ahmed Piche evaporimeter had all the same annual average reference evaporation of $1460 \mathrm{~mm} \mathrm{y}^{-1}$ (Figure 3). The predictions of the Blaney-Criddle and Thornthwaite are slightly more at $1754 \mathrm{~mm} \mathrm{y}^{-1}$ (Figure 3). The last three

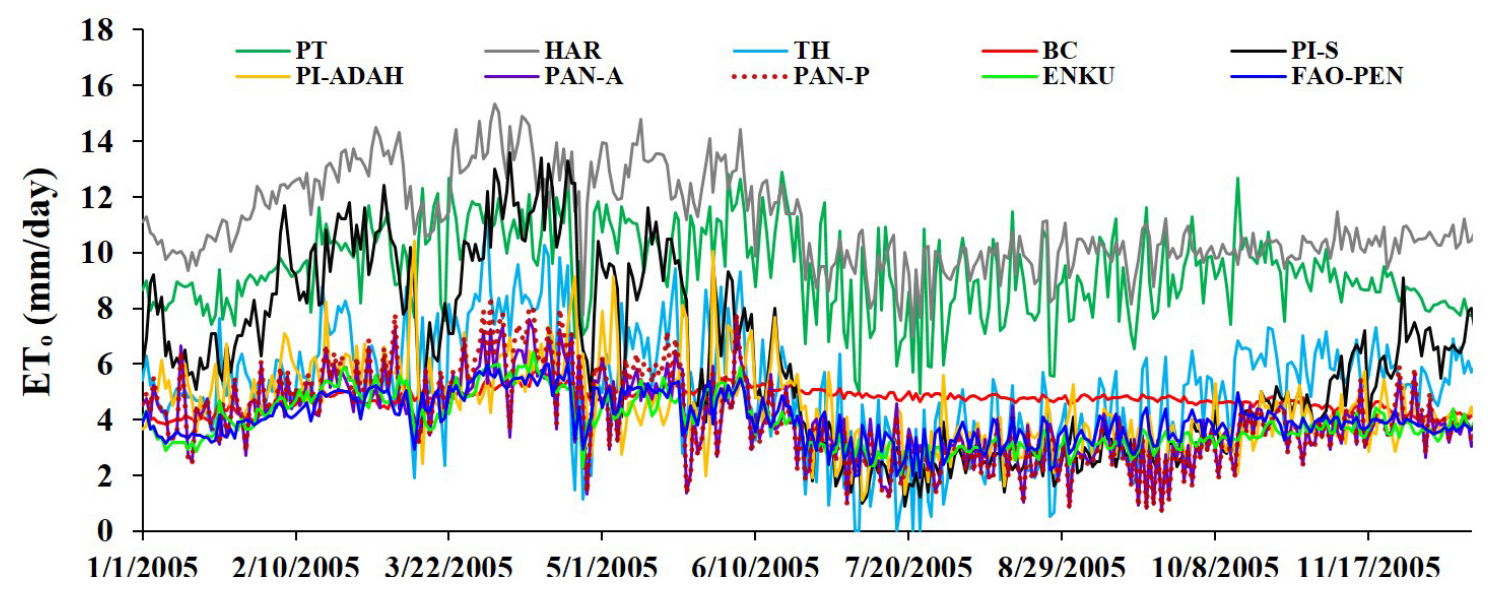

Figure 1. Daily plot of reference potential evaporation $\left(\mathrm{ET}_{0}\right)$ of the ten methods for 2005 for the Bahir Dar meteorological station. The following abbreviations are used: FAO-PEN is FAO-Penman Monteith (Equation (1)), PT is Priestley \& Taylor (Equation (2)), HAR is Hargraves (Equation (5)), TH is Thornthwaite (Equation (9)), BC is Blaney-Criddle (Equation (10)), ENKU is the Enku's simple temperature method (Equation (11)), PAN-P is the Pan-Pereira (Equation (12)), PAN-A is the Pan-Allen (Equation (14)), PI-S is the Piche-Stanhill (Equation (16)) and PI-ADAH is the Piche-Adam and Ahmed (Equation (20)). 


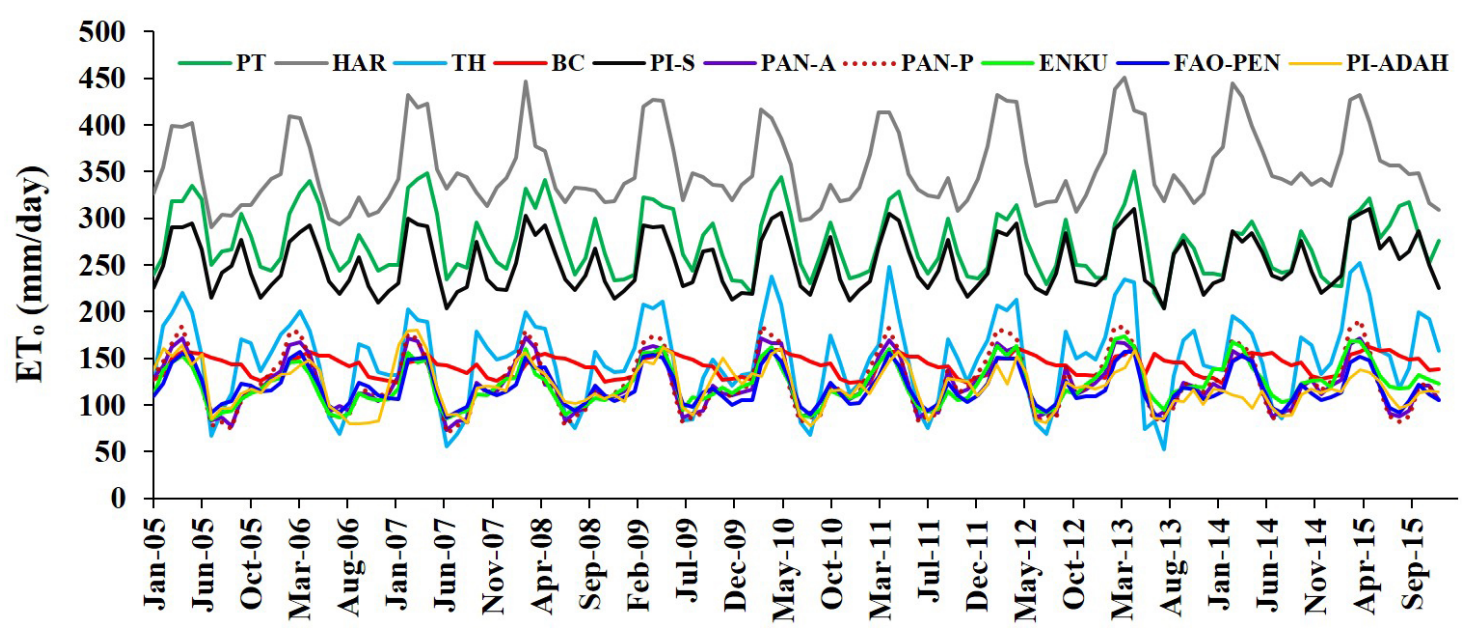

Figure 2. Monthly plot of $\mathrm{ET}_{0}$ of the ten methods for the Bahir Dar meteorological station from 2005 to 2015. Abbreviations of the reference evaporation methods are listed under Figure 1.

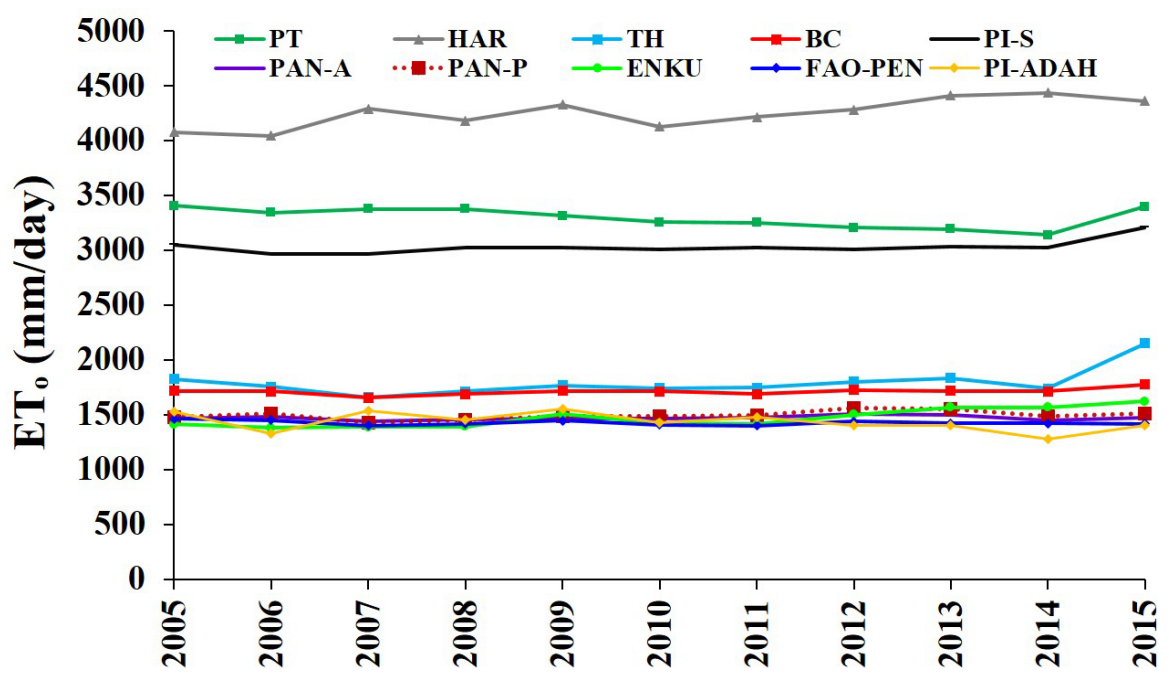

Figure 3. Annual reference evaporation, $\mathrm{ET}_{0}$, of the ten methods for the Bahir Dar meteorological station from 2005 to 2015 . Abbreviations of the reference evaporation methods are listed under Figure 1.

methods also over predicted pan evaporation in the Ethiopian highlands: the Stanhill Piche evaporimeter method predicted on the average $1571 \mathrm{~mm} \mathrm{y}^{-1}$, Priestley \& Taylor methods as $1838 \mathrm{~mm} \mathrm{y}^{-1}$ and Hargraves almost twice the pan evaporation $\mathrm{ET}_{0}$ at $2792 \mathrm{~mm} \mathrm{y}^{-1}$. In addition, Figure 3 showed that the year to year variation in reference evaporation was small, indicating that the amount of rainfall and soil moisture have little or no effect on the loss of water in the atmosphere.

\section{Discussion}

\subsection{Reference Evaporation: Comparing the Methods}

The data in Figure 2 are further summarized in Figure 4 where the monthly averaged reference evaporation, $\mathrm{ET}_{0}$, of each of the 10 methods for the eleven years 


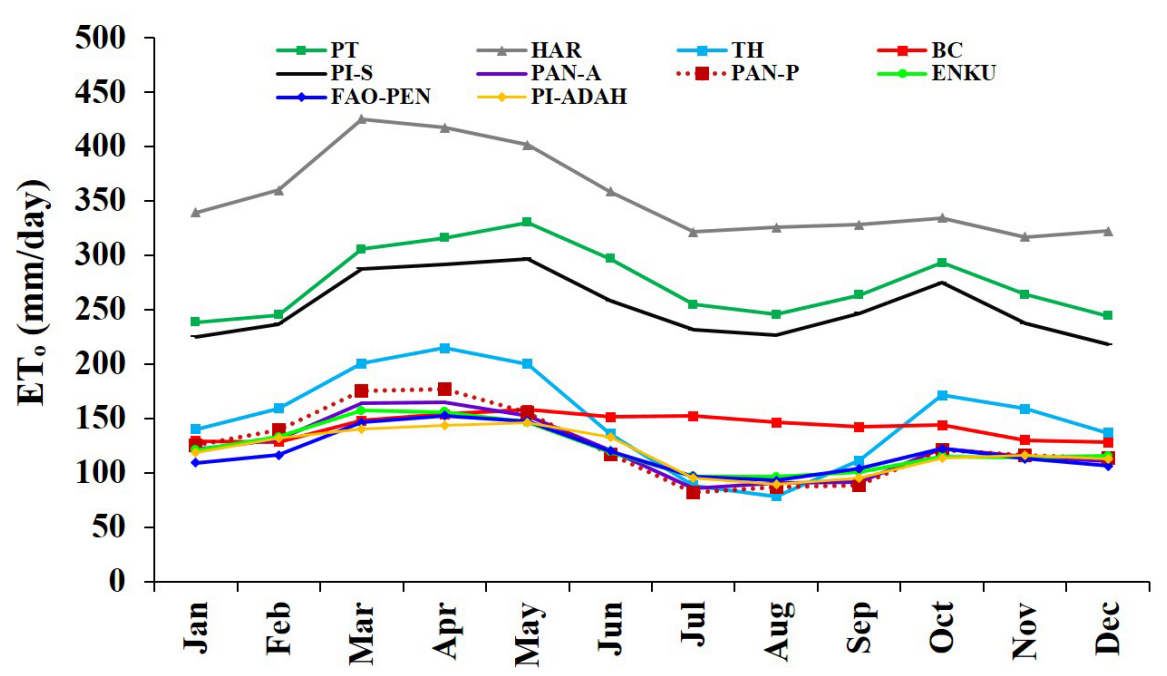

Figure 4. Long-term mean monthly evapotranspiration (2005-2015) of Bahir Dar for ten different prediction techniques. Abbreviations of the reference evaporation methods are explained Figure 1.

(2005-2015) are depicted. As in Figure 2 the Hargraves (HR), the Priestley \& Taylor (PT) and the Piche-Stanhill method (PI-S) over predicts the reference evaporation greatly and will not be discussed in any detail. These three methods should not be applied in the Ethiopian highlands to calculate evaporation.

While all methods have the smallest reference evaporation during the rain phase (Figure 4), the Blaney-Criddle (blue solid line) is the exception. At the end of dry phase, the $\mathrm{ET}_{0}$ calculated with the Blaney-Criddle method is in the same order as other indirect measurement that predicts realistically $\mathrm{ET}_{0}$ such as the FAO-Penman and the Enku methods, but severely over predicts during the rain phase. It has also the smallest variability compared to all other methods (Figure 4). The reason is that the reference evaporation is calculated as linear function of the average monthly temperature (Equation (10)) which in the countries near the equator varies little during the year and thus the $\mathrm{ET}_{0}$ values are within a narrow band as well (Figure 4, Figure 5). By replacing the constant values for the whole year in the Blaney-Criddle equation (Equation (10)), by monthly varying constants and calibrating these, the model will fit much better [48]. The modified Blaney-Criddle Equation becomes in this way similar to the Enku method (Equation (11)). Interestingly, in Figure 4 has shown that during the rain phase starting in May (when the first rains fell) through September (when the rains ended), the reference evaporation, $\mathrm{ET}_{0}$, calculated with the three indirect methods (the FAO-Penman Monteith, the Thornthwaite and the Enku methods) compared well with the direct measurement of both pan evaporation methods and the Piche evaporimeter using coefficients proposed by Adam and Ahmed [14].

During the rain phase when precipitation exceeds evaporation, the condition of a well-watered surface on which the reference evaporation is based is similar to that in the Ethiopian highlands. So, during the wet phase the direct and indirect 


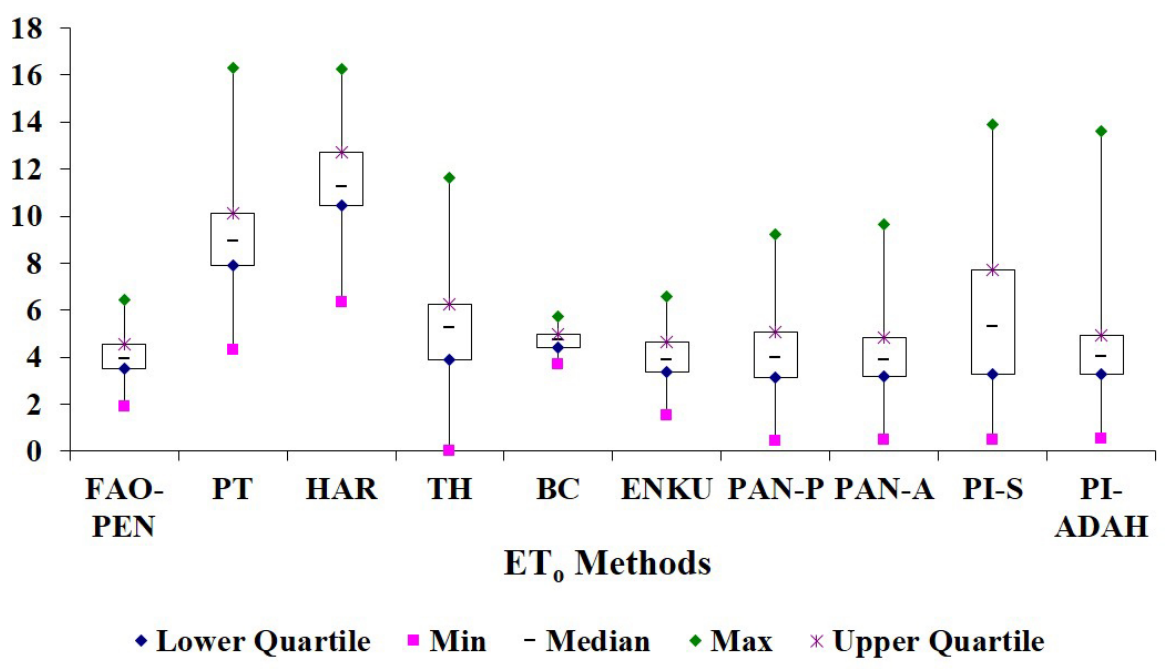

Figure 5. Box plots of daily $\mathrm{ET}_{0}$ prediction methods for the Bahir Dar weather station. Abbreviations of the reference evaporation methods are explained Figure 1.

measurements should agree and they do for the FAO-Penman Monteith, the Thornthwaite and the Enku methods with the two pan methods and one of the Piche methods (Figure 4). During the dry phase, the reference evaporation for these seven methods started to deviate. Initially after the rains stopped and the surface of soil was still wet, only the Thorntwaite method predicted higher $\mathrm{ET}_{0}$ values while the remaining five agreed well. In January to April when the landscape is very dry and rivers are without water, the direct measurements of the $\mathrm{ET}_{0}$ are much greater than the calculated values using the meteorological data (Figure 4). The reason for the deviation can be explained with the complementary relationship of actual evaporation and apparent (or pan) evaporation originally introduced by Bouchet [49] and refined by Brutsaert and Stricker [50]. The theory is as follows: When the soil is dry and the evaporation is less than the reference evaporation, the energy that under wet conditions is used for evaporation is converted to the sensible heat and causes an increase in the evaporative demand of the atmosphere. The reference evaporation rates derived from the pan during the dry season are therefore greater than it would be during the wet season under otherwise similar atmospheric conditions. The FAO-Penman method predicts reference evaporation rates of a well-watered irrigation field independent of the condition of the landscape. Hence, the discrepancy between the direct and indirect methods under extreme dry conditions in the period is from January through April (Figure 4).

The question whether the direct or indirect measurement of the reference evaporation is more appropriate during the dry phase is a mood point because the evaporation for most of the landscape, where the soil is dry, is limited by the soil and not by the atmosphere. Only for irrigated fields and lakes, the reference evaporation determines the rate of evaporation during the dry phase. As pointed out by Bouchet [49] the upward wind site of an irrigated field, the evaporation rate is similar to the pan measurement while in the remaining of the area the 
evaporation rate is equal to reference evaporation calculated with the Penman Monteith.

In addition to plotting the averaged reference evaporation, $\mathrm{ET}_{0}$, in Figure 5, it is also of interesting to investigate the variation in the reference evaporation for each of the 10 methods. Therefore, the maximum, minimum, mean, lower and upper quartile of the long term daily reference evaporation for the period are shown in Figure 5 from 2005 to the end of 2015. Figure 5 indicates that the Blaney-Criddle method has the least variation because it is only dependent of the average temperature that (despite what the Ethiopians claim) varies little throughout the year. The FAO-Penman Monteith has only a slightly larger variation in $\mathrm{ET}_{0}$ than the Blaney-Criddle method because it calculates likewise the $\mathrm{ET}_{0}$ based on meteorological variables that vary little throughout the year except for the cloud cover which is the reason of the additional spread in $\mathrm{ET}_{0}$ values. The Enku method that depends on temperature has a larger variation than the Blaney-Criddle, because besides temperature it is dependent on a few other fitted functions so that it can simulate the lower $\mathrm{ET}_{0}$ during the month with clouds. The two pan measurements have a large variation, because they are based on measured data. The measured $\mathrm{ET}_{0}$ values have a large spread because of the sensible heat during the dry phase that increases the pan evaporation but is not included in any of the indirect methods.

In the Pearson correlation statistics, we looked the performance of eight reference evaporation methods with the pan evaporation methods (Table 1). As expected form the discussion above, the FAO-Penman Monteith and Enku simple maximum temperature methods were highly correlated with correlation coefficient of respectively 0.91 and 0.93 (monthly), and 0.64 and 0.69 (daily). Thornthwaite method holds the third place of good $\mathrm{ET}_{0}$ monthly estimator with correlation of 0.89 for both pan $\mathrm{ET}_{0}$ methods on a monthly basis.

Rácz et al. [15] stated that methods having smallest RMSE have the lowest systematic error in predicting $\mathrm{ET}_{0}$. Table 2 confirms our findings above that the Penman, Enku, Piche and Pan are most similar because they have the smallest RMSE (Table 2). It is surprising that the Blaney-Criddle model has such a small RMSE with the pan on daily time step. It is quirk of how the daily $\mathrm{ET}_{0}$ values are calculated.

Table 1. Pearson's correlation between $\mathrm{Pan}^{\mathrm{ET}_{0}}$ and $\mathrm{ET}_{0}$ of prediction methods (20052015).

\begin{tabular}{ccccccccc}
\hline & PEN & PT & HAR & TH & BC & ENKU & PI-S & PI-ADAH \\
\hline & & \multicolumn{7}{c}{ Daily-Basis } \\
\hline PAN-P & 0.64 & 0.42 & 0.63 & 0.55 & 0.22 & 0.69 & 0.72 & 0.47 \\
PAN-A & 0.59 & 0.43 & 0.57 & 0.51 & 0.23 & 0.62 & 0.65 & 0.49 \\
\hline & & & & Monthly-Basis & & & \\
\hline PAN-P & 0.91 & 0.58 & 0.84 & 0.89 & 0.21 & 0.93 & 0.7 & 0.75 \\
PAN-A & 0.93 & 0.65 & 0.84 & 0.89 & 0.26 & 0.91 & 0.75 & 0.79 \\
\hline
\end{tabular}


Table 2. Root mean square error (RMSE) between modeled daily $\mathrm{ET}_{0}$ and pan $\mathrm{ET}_{0}$ (20052015).

\begin{tabular}{ccccccccc}
\hline & PEN & PT & HAR & TH & BC & ENKU & PI-S & PI-ADAH \\
\hline \multicolumn{7}{c}{ Daily-Basis } \\
\hline PAN-P & 0.59 & 1.44 & 1.23 & 1.61 & 0.37 & 0.63 & 1.99 & 1.16 \\
PAN-A & 0.62 & 1.43 & 1.3 & 1.66 & 0.37 & 0.69 & 2.18 & 1.15 \\
\hline & & \multicolumn{7}{c}{ Monthly-Basis } \\
\hline PAN-P & 8.1 & 28.2 & 22.2 & 21.1 & 11 & 8.5 & 20.7 & 15.6 \\
PAN-A & 7.5 & 26.3 & 22.6 & 21.2 & 10.9 & 9.5 & 19.4 & 14.4 \\
\hline
\end{tabular}

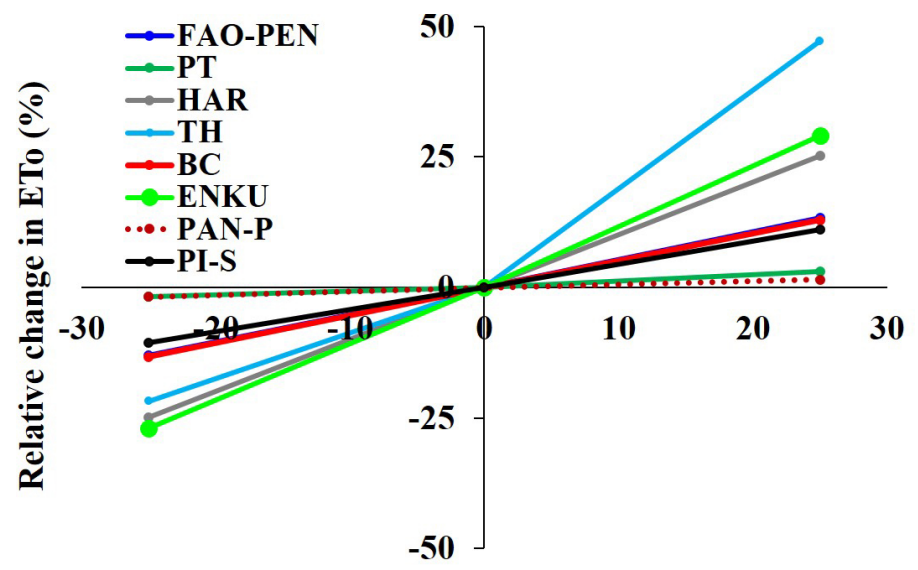

Relative change in temperature (\%)

Figure 6. Relative change in reference potential evaporation of Bahir Dar station for the change of temperature between the year 2005 and 2015. Abbreviations of the reference evaporation methods are explained Figure 1.

\subsection{Sensitivity Analysis}

In the sensitivity analysis, we looked the relative effect on reference evaporation of a $25 \%$ change in temperature, sunshine hours, relative humidity and wind speed (Figure 6, Figure S2). As expected, an increase in temperature increased reference evaporation (Figure 6). For the indirect methods (Enku, Thornthwaite and Hargreaves methods), the reference evaporation increased the same percentage or more as the temperature. The direct methods were the least sensitive to the change in temperature. Changing sunshine hours, relative humidity and wind speed did not change or increased the reference evaporation with the exception that an increase in relatively humidity for the FAO-Penman Monteith and an increase in winds Speed for both pan methods decreased the reference evaporation (Figure S2).

\subsection{Trend Analysis}

The trend analysis results of the reference potential evaporation obtained by applying the Mann-Kendall method is shown in Table 3. To our surprise despite our short 11-year record, there were strong trends for the majority of the 10 
Table 3. Mann Kendall trend test statistics for daily $\mathrm{ET}_{0}$ of Bahir Dar station from 2005 to 2015 .

\begin{tabular}{ccccccc}
\hline ET $_{0}$ Methods & $\begin{array}{c}\text { Mann-Kendall } \\
\text { Statistic (S) }\end{array}$ & $\begin{array}{c}\text { Kendall's } \\
\text { Tau }\end{array}$ & Var (S) & $\begin{array}{c}\text { p-Value (Two } \\
\text { Tailed Test) }\end{array}$ & $\begin{array}{c}\text { Alpha } \\
\text { Interpretation }\end{array}$ \\
\hline FAO-PEN & 0.041 & 327,438 & $7,199,473,160$ & 0.0001 & 0.05 & Reject $\mathrm{H}_{0}$ \\
PT & -0.063 & $-507,950$ & $7,199,473,160$ & $<0.0001$ & 0.05 & Reject $\mathrm{H}_{0}$ \\
HAR & 0.085 & 682,662 & $7,199,473,160$ & $<0.0001$ & 0.05 & Reject $\mathrm{H}_{0}$ \\
TH & 0.046 & 367,257 & $7,199,469,652$ & $<0.0001$ & 0.05 & Reject $\mathrm{H}_{0}$ \\
BC & 0.053 & 427,721 & $7,199,382,783$ & $<0.0001$ & 0.05 & Reject $\mathrm{H}_{0}$ \\
ENKU & 0.126 & $1,000,816$ & $7,193,567,805$ & $<0.0001$ & 0.05 & Reject $\mathrm{H}_{0}$ \\
PAN-P & 0.010 & 79,504 & $7,199,473,160$ & 0.3488 & 0.05 & Accept $\mathrm{H}_{0}$ \\
PAN-A & -0.012 & $-95,502$ & $7,199,473,158$ & 0.2604 & 0.05 & Accept $\mathrm{H}_{0}$ \\
PI-S & -0.050 & $-401,899$ & $7,198,567,007$ & $<0.0001$ & 0.05 & Reject $\mathrm{H}_{0}$ \\
PI-ADAH & -0.071 & $-571,885$ & $7,199,470,202$ & $<0.0001$ & 0.05 & Reject $\mathrm{H}_{0}$ \\
\hline
\end{tabular}
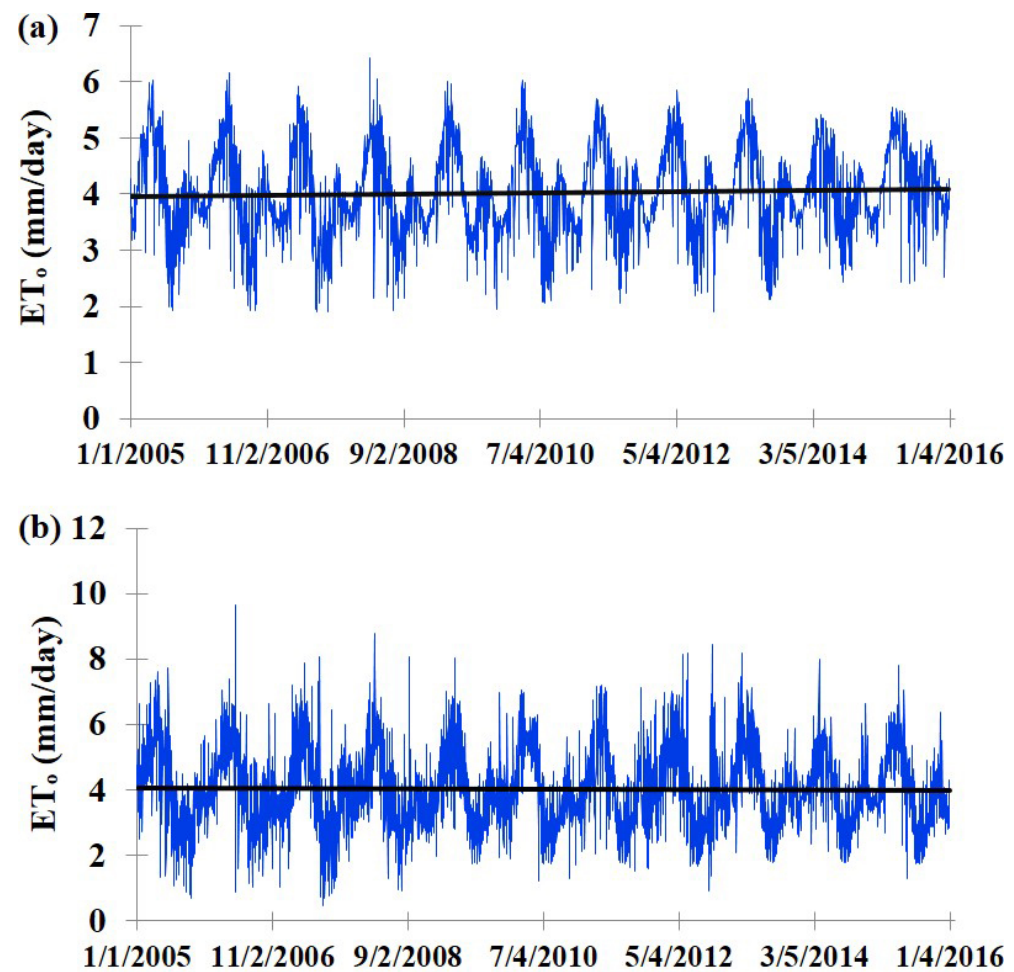

Figure 7. Time series plots of $\mathrm{ET}_{0}$ for Bahir Dar station from 2005 to 2015: (a) FAO-Penman Monteith; (b) Pan-Pereira.

methods. Only the direct measurement of the $\mathrm{ET}_{0}$ with the two pan methods did not change over the eleven year period (i.e., accept the null hypothesis that there is not a trend in the $\mathrm{ET}_{0}$ values, Table 3, Figure 7(b)). Methods that calculated the reference evaporation from meteorological data (e.g., FAO-Penman Monteith (FAO-PEN), Hargraves (HAR), Thornthwaite (TH), Blaney-Criddle (PT), Enku (ENKU)) increased with time (Table 3, Figure 7(a) and Figure S3). The 
Priestly and Taylor methods that was ill suited for the Ethiopian highlands was an exception. Thus, since these methods were directly based on measured meteorological data (two only on temperature) it clearly indicates that the climate is changing in the Ethiopian Highlands. In other words, since three of the indirect methods were primarily based on temperature, it is getting warmer fast in Bahir Dar! Finally, the Piche methods that not directly depend on the measured standard indicated that the reference evaporation was decreasing.

This paradox of increasing reference evaporation calculated by indirect methods and either not changing (both pan measurements) or decreasing (Piche measurement) by direct measurement has been noted before in a slightly different context by Brutsaert and Parlange [51] as one of the first. They noted that pan evaporation rates were generally decreasing and related that to increased terrestrial evaporation because more runoff occurring with climate change. In terms of the complementary relationship introduced earlier, they explain that more of the incoming energy is used for evaporation and consequently less is converted to sensible heat. This in turn reduces pan evaporation. For the Bahir Dar meteorological station, the explanation might be slightly different. Temperatures in Bahir Dar are increasing either due to climate change or because of rapid urbanization. The dry season has been always so dry that all evaporative energy was converted to sensible heat and increasing temperatures did not affect pan evaporation. The Piche evaporimeter measurements were likely not affected either by the higher temperatures but the relatively humidity decreased due to the higher temperature decreasing the $\mathrm{ET}_{0}$ value as can be seen from Equation (20).

\section{Conclusions}

Ten methods to predict the reference evaporation were tested for the Ethiopian highlands. The Priestley and Taylor, Hargreaves, and Piche-Stanhill methods over predicted $\mathrm{ET}_{0}$ and should not be used without recalibration. In addition, the Blaney-Criddle method over predicted the reference evaporation during the rain phase. The reference evaporation calculated with the FAO-Penman and Enku methods resembles most closely the direct measurements with the Class A pan evaporation using confident introduced by Pareira and Allen. Thorthwaite's monthly $\mathrm{ET}_{0}$ model performed well too.

A significant increasing trend in calculated reference evaporation using meteorological variables was found, indicating that temperatures were increasing during the past 11 years at the Bahir Dar weather station. The direct measurement by the Class A pan did not show this trend. More research is needed to research whether other parts of the Ethiopian highlands show similar trends in reference evaporation.

Our recommendation is that the FAO-Penman Monteith is recommended for locations where the input data are available. Otherwise, the Enku method using maximum daily temperature is best for estimating the reference evaporation. 


\section{Acknowledgements}

Authors gratefully acknowledge the Ethiopian National Meteorological Agency (NMA)-Bahir Dar Meteorology Directorate for providing the meteorological datasets of Bahir Dar principal station. The frank discussion on evaporation methods with Professor Brutsaert was very helpful.

\section{References}

[1] Un-Water-Africa (2003) The Africa Water Vision for 2025: Equitable and Sustainable Use of Water for Socioeconomic Development. Economic Commission for Africa, Addis Ababa.

[2] Sutcliffe, J.V. and Parks, Y.P. (1999) The Blue Nile and Its Tributaries. IAHS Special Publication.

[3] Abtew, W. and Melesse, A.M. (2014) The Nile River Basin. Nile River Basin. Springer. https://doi.org/10.1007/978-3-319-02720-3_2

[4] Meyer, W.S. (1999) Standard Reference Evaporation Calculation for Inland, South Eastern Australia, CSIRO Land and Water.

[5] Pereira, A.R., Nova, N.A.V., Pereira, A.S. and Barbieri, V. (1995) A Model for the Class A Pan Coefficient. Agricultural and Forest Meteorology, 76, 75-82.

[6] Allen, R.G., Pereira, L.S., Raes, D. and Smith, M. (1998) Crop Evapotranspiration-Guidelines for Computing Crop Water Requirements-FAO Irrigation and Drainage Paper 56. FAO, Rome, 300, D05109.

[7] Fisher, D.K. and Pringle Iii, H. (2013) Evaluation of Alternative Methods for Estimating Reference Evapotranspiration. Agricultural Sciences, 4, 51.

https://doi.org/10.4236/as.2013.48A008

[8] Jensen, M.E., Burman, R.D. and Allen, R.G. (1990) Evapotranspiration and Irrigation Water Requirements. ASCE Manulas and Reports on Engineering Practice, New York. ASCE, New York, 311-327.

[9] Smith, M., Segeren, A., Santos Pereira, L., Perrier, A. and Allen, R. (1991) Report on the Expert Consultation on Procedures for Revision of FAO Guidelines for Prediction of Crop Water Requirements. Rome, 28-31 May 1990.

[10] Djaman, K., Tabari, H., Balde, A.B., Diop, L., Futakuchi, K. and Irmak, S. (2016) Analyses, Calibration and Validation of Evapotranspiration Models to Predict Grass-Reference Evapotranspiration in the Senegal River Delta. Journal of Hydrology. Regional Studies, 8, 82-94.

[11] Gotardo, J.T., Rodrigues, L.N. and Gomes, B.M. (2016) Comparison of Methods for Estimating Reference Evapotranspiration: An Approach to the Management of Water Resources within an Experimental Basin in the Brazilian Cerrado. Engenharia Agrícola, 36, 1016-1026. https://doi.org/10.1590/1809-4430-eng.agric.v36n6p1016-1026/2016

[12] Pandey, P.K., Dabral, P.P. and Pandey, V. (2016) Evaluation of Reference Evapotranspiration Methods for the Northeastern Region of India. International Soil and Water Conservation Research, 4, 52-63.

[13] Stanhill, G. (1962) The Use of the Piche Evaporimeter in the Calculation of Evaporation. Quarterly Journal of the Royal Meteorological Society, 88, 80-82. https://doi.org/10.1002/qj.49708837508

[14] Adam, H.S. and Ahmed, S.M. (2014) Use of Piche Evaporation in a Stevenson Screen to Estimate Reference Evapotranspiration in the Sudan. Sudanese Journal of 
Agricultural Sciences, 2014, 70-76.

[15] Rácz, C., Nagy, J. and Dobos, A.C. (2013) Comparison of Several Methods for Calculation of Reference Evapotranspiration. Acta Silvatica et Lignaria Hungarica, 9, 9-24. https://doi.org/10.2478/aslh-2013-0001

[16] Silva, D., Meza, F.J. and Varas, E. (2010) Estimating Reference Evapotranspiration (ETo) using Numerical Weather Forecast Data in Central Chile. Journal of Hydrology, 382, 64-71.

[17] Hashem, A., Engel, B., Bralts, V., Radwan, S. and Rashad, M. (2016) Performance Evaluation and Development of Daily Reference Evapotranspiration Model. Irrigation \& Drainage Systems Engineering, 5, 1-6.

[18] Bogawski, P. and Bednorz, E. (2014) Comparison and Validation of Selected Evapotranspiration Models for Conditions in Poland (Central Europe). Water Resources Management, 28, 5021-5038. https://doi.org/10.1007/s11269-014-0787-8

[19] Enku, T. and Melesse, A.M. (2014) A Simple Temperature Method for the Estimation of Evapotranspiration. Hydrological Processes, 28, 2945-2960.

http://onlinelibrary.wiley.com/doi/10.1002/hyp.9844

[20] Djaman, K., Balde, A.B., Sow, A., Muller, B., Irmak, S., N'diaye, M.K., Manneh, B., Moukoumbi, Y.D., Futakuchi, K. and Saito, K. (2015) Evaluation of Sixteen Reference Evapotranspiration Methods under Sahelian Conditions in the Senegal River Valley. Journal of Hydrology: Regional Studies, 3, 139-159.

[21] Čadro, S., Uzunović, M., Žurovec, J. and Žurovec, O. (2017) Validation and Calibration of Various Reference Evapotranspiration Alternative Methods under Bosnia and Herzegovina Climate Conditions. International Soil and Water Conservation Research.

[22] Xing, Z., Chow, L., Meng, F.-R., Rees, H.W., Steve, L. and Monteith, J. (2008) Validating Evapotranspiraiton Equations using Bowen Ratio in New Brunswick, Maritime, Canada. Sensors, 8, 412-428. https://doi.org/10.3390/s8010412

[23] Douglas, E.M., Jacobs, J.M., Sumner, D.M. and Ray, R.L. (2009) A Comparison of Models for Estimating Potential Evapotranspiration for Florida Land Cover Types. Journal of Hydrology, 373, 366-376.

[24] Razzaghi, F. and Sepaskhah, A.R. (2010) Assessment of Nine Different Equations for ETo Estimation using Lysimeter Data in a Semi-Arid Environment. Archives of Agronomy and Soil Science, 56, 1-12. https://doi.org/10.1080/03650340902829180

[25] Razzaghi, F. and Sepaskhah, A.R. (2012) Calibration and Validation of Four Common ET0 Estimation Equations by Lysimeter Data in a Semi-Arid Environment. Archives of Agronomy and Soil Science, 58, 303-319. https://doi.org/10.1080/03650340.2010.518957

[26] Melesse, A.M., Abtew, W. and Dessalegne, T. (2009) Evaporation Estimation of Rift Valley Lakes: Comparison of Models. Sensors, 9, 9603-9615. https://doi.org/10.3390/s91209603

[27] Worqlul, A.W., Ayana, E.K., Maathuis, B.H., Macalister, C., Philpot, W.D., Leyton, J.M.O. and Steenhuis, T.S. (2017) Performance of Bias Corrected MPEG Rainfall Estimate for Rainfall-Runoff Simulation in the Upper Blue Nile Basin, Ethiopia. Journal of Hydrology.

[28] Worqlul, A.W., Yen, H., Collick, A.S., Tilahun, S.A., Langan, S. and Steenhuis, T.S. (2017) Evaluation of CFSR, TMPA 3B42 and Ground-Based Rainfall Data as Input for Hydrological Models, in Data-Scarce Regions: The Upper Blue Nile Basin, Ethiopia. Catena, 152, 242-251.

[29] Hurni, H. (1988) Degradation and Conservation of the Resources in the Ethiopian 
Highlands. Mountain Research and Development, 123-130. https://doi.org/10.2307/3673438

[30] Nyssen, J., Vandenreyken, H., Poesen, J., Moeyersons, J., Deckers, J., Haile, M., Salles, C. and Govers, G. (2005) Rainfall Erosivity and Variability in the Northern Ethiopian Highlands. Journal of Hydrology, 311, 172-187.

[31] Grosjean, M. and Messerli, B. (1988) African Mountains and Highlands: Potential and Constraints. Mountain Research and Development, 8, 111-122. https://doi.org/10.2307/3673437

[32] Hawando, T. (1997) Desertification in Ethiopian Highlands. Rala Report, No. 200, 75-86.

[33] Priestley, C. and Taylor, R. (1972) On the Assessment of Surface Heat Flux and Evaporation using Large-Scale Parameters. Monthly Weather Review, 100, 81-92. https://doi.org/10.1175/1520-0493(1972)100<0081:OTAOSH>2.3.CO;2

[34] Mcnaughton, K. and Jarvis, P. (1983) Predicting Effects of Vegetation Changes on Transpiration and Evaporation. Water Deficits and Plant Growth, 7, 1-47.

[35] Hargreaves, G.H. and Samani, Z.A. (1985) Reference Crop Evapotranspiration from Temperature. Applied Engineering in Agriculture, 1, 96-99. https://doi.org/10.13031/2013.26773

[36] Thornthwaite, C.W. (1948) An Approach toward a Rational Classification of Climate. Geographical Review, 38, 55-94. https://doi.org/10.2307/210739

[37] Brouwer, C. and Heibloem, M. (1986) Irrigation Water Management: Irrigation Water Needs. Training Manual, Food and Agriculture Organization of the United Nations, Rome, 3.

[38] Papaioannou, G., Vouraki, K. and Kerkides, P. (1996) Piche Evaporimeter Data as a Substitute for Penman Equation's Aerodynamic Term. Agricultural and Forest Meteorology, 82, 83-92.

[39] Wmo (2010) Guide to Agricultural Meteorological Practices World Meteorological Organization (WMO), WMO-No. 134, Geneva 2.

[40] Penman, H.L. (1948) Natural Evaporation from Open Water, Bare Soil and Grass. Proceedings of the Royal Society of London A: Mathematical, Physical and Engineering Sciences, The Royal Society, 120-145.

[41] Penman, H.L. (1963) Vegetation and Hydrology. Soil Science, 96, 357. https://doi.org/10.1097/00010694-196311000-00014

[42] Suhaila, J., Deni, S.M., Zin, W.Z.W. and Jemain, A.A. (2010) Trends in Peninsular Malaysia Rainfall Data during the Southwest Monsoon and Northeast Monsoon Seasons: 1975-2004. Sains Malaysiana, 39, 533-542.

[43] Sulaiman, N.H., Kamarudin, M.K.A., Mustafa, A.D., Amran, M.A., Azaman, F., Abidin, I.Z. and Hairoma, N. (2015) Trend Analysis of Pahang River Using Non-Parametric Analysis: Mann Kendall's Trend Test. Malaysian Journal of Analytical Sciences, 19, 1327-1334.

[44] Mann, H.B. (1945) Nonparametric Tests against Trend. Econometrica: Journal of the Econometric Society, 245-259. https://doi.org/10.2307/1907187

[45] Kendall, M.G. (1948) Rank Correlation Methods. British Journal of Statistical Psychology, 9.

[46] Kendall, M.G. and Stuart, A. (1967) The Advanced Theory of Statistics, 2nd Edition, Hafner, New York.

[47] Doorenbos, J. and Pruitt, W. (1977) Crop Water Requirements. FAO Irrigation and 
Drainage Paper 24. Land and Water Development Division, FAO, 144.

[48] Fooladman, H.R. (2011) Evaluation of Blaney-Criddle Equation for Estimating Evapotranspiration in South of Iran. African Journal of Agricultural Research, 6, 3103-3109.

[49] Bouchet, R.J. (1963) Evapotranspiration réelle et potentielle, signification climatique. [Actual and Potential Evaporation, Climatic Significant.] IAHS Publ, 62, 134-142.

[50] Brutsaert, W. and Stricker, H. (1979) An Advection-Aridity Approach to Estimate Actual Regional Evapotranspiration. Water Resources Research, 15, 443-450. https://doi.org/10.1029/WR015i002p00443

[51] Brutsaert, W. and Parlange, M. (1998) Hydrologic Cycle Explains the Evaporation Paradox. Nature, 396, 30. https://doi.org/10.1038/23845 


\section{Supplementary Materials}

Supplementary Material S1: Parameters of FAO-Penman Monteith Equation

The slope of the relationship between saturation vapor pressure and temperature, $\Delta$, is

$$
\Delta=\frac{4098\left[0.6108 \exp \left(\frac{14.27 T}{T+237.3}\right)\right]}{(T+237.3)^{2}}
$$

where, $T$ air temperature $\left[{ }^{\circ} \mathrm{C}\right]$. The actual vapor pressure can be determined from the difference between the dry and wet bulb temperatures, $e_{a}$

$$
e_{a}=\frac{R H_{\text {mean }}}{100}\left[\frac{e^{o}\left(T_{\max }\right)+e^{o}\left(T_{\min }\right)}{2}\right]
$$

where $e_{a}$ actual vapor pressure $[\mathrm{kPa}], e^{o}\left(T_{\min }\right)$ saturation vapor pressure at daily minimum temperature $[\mathrm{kPa}], e^{o}\left(T_{\max }\right)$ saturation vapor pressure at daily maximum temperature [kPa], $R H_{\text {mean }}$ is the mean relative humidity, defined as the average between $R H_{\max }$ and $R H_{\text {min }}$.

As saturation vapor pressure is related to air temperature, it can be calculated from the air temperature. The relationship is expressed by:

$$
e^{o}(T)=0.6108 \exp \left[\frac{14.27 T}{T+237.3}\right]
$$

where $e^{o}(T)$ saturation vapour pressure at the air temperature $T[\mathrm{kPa}], T$ air

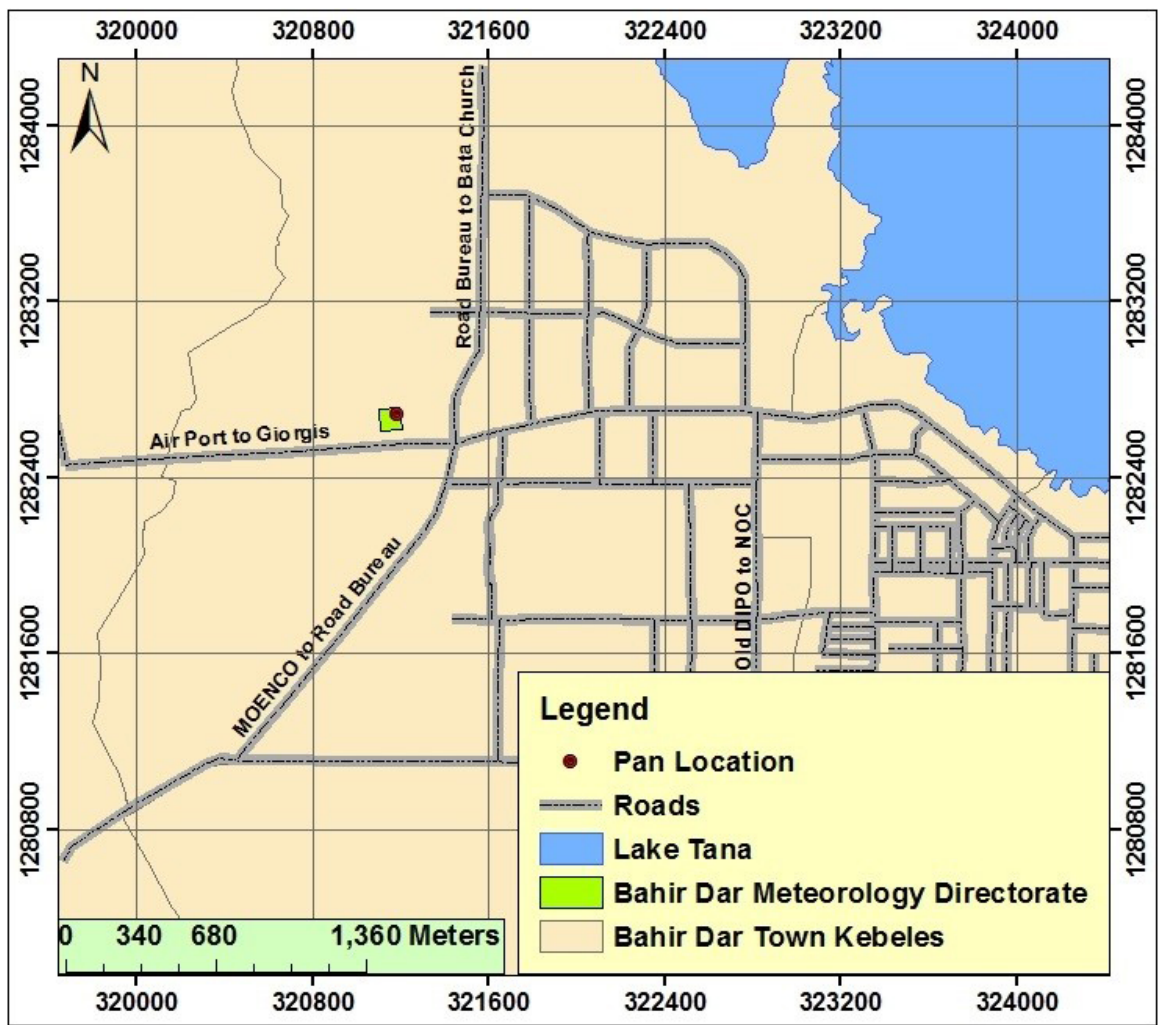

Figure S1. Location of Bahir Dar principal meteorological station. 
Table S1. Data used and overview of $\mathrm{ET}_{0}$ methods calculation.

\begin{tabular}{|c|c|c|c|c|c|c|c|c|c|c|c|c|c|}
\hline Date & $\begin{array}{l}\text { Tmax, } \\
{ }^{\circ} \mathrm{C}\end{array}$ & $\stackrel{\operatorname{Tmin},}{{ }^{\circ} \mathrm{C}}$ & $\begin{array}{l}\text { Sunshine } \\
\text { (hour) }\end{array}$ & $\begin{array}{l}\text { Humidity } \\
(\%)\end{array}$ & $\begin{array}{l}\text { Wind speed at } 2 \mathrm{~m} \\
\mathrm{~m} / \mathrm{s}\end{array}$ & $\begin{array}{c}\mathrm{T} \\
\text { mean }\end{array}$ & $\begin{array}{c}\Delta \\
\left(\mathrm{Kpa} /{ }^{\circ} \mathrm{C}\right)\end{array}$ & $\begin{array}{c}\text { Elevation } \\
(\mathrm{m})\end{array}$ & $\mathrm{P}(\mathrm{KP})$ & $\begin{array}{c}\mathrm{Y} \\
\left(\mathrm{Kpa} /{ }^{\circ} \mathrm{C}\right)\end{array}$ & $e^{\bullet}(\operatorname{Tmax})$ & $\begin{array}{c}\mathrm{e}^{\bullet} \\
(\mathrm{T} \min )\end{array}$ & $\square$ \\
\hline $12 / 30 / 2005$ & 28.0 & 7.1 & 10.4 & 38 & 1.2 & 17.6 & 0.13 & 1805 & 78.16 & 0.052 & 3.78 & 1.01 & $\rightarrow$ \\
\hline $12 / 31 / 2005$ & 26.3 & 6.7 & 10.2 & 36 & 1.0 & 16.5 & 0.12 & 1805 & 78.16 & 0.052 & 3.42 & 0.98 & $\rightarrow$ \\
\hline $1 / 1 / 2006$ & 26.7 & 5.6 & 10.3 & 37 & 0.9 & 16.2 & 0.12 & 1805 & 78.15 & 0.052 & 3.50 & 0.91 & $\rightarrow$ \\
\hline $1 / 2 / 2006$ & 26.3 & 5.5 & 10.3 & 40 & 1.0 & 15.9 & 0.12 & 1805 & 78.14 & 0.052 & 3.42 & 0.90 & $\rightarrow$ \\
\hline $1 / 3 / 2006$ & 27.6 & 8.1 & 10.4 & 36 & 1.0 & 17.9 & 0.13 & 1805 & 78.13 & 0.052 & 3.69 & 1.08 & $\rightarrow$ \\
\hline $1 / 4 / 2006$ & 27.2 & 6.5 & 10.0 & 36 & 1.0 & 16.9 & 0.12 & 1805 & 78.12 & 0.052 & 3.61 & 0.97 & $\rightarrow$ \\
\hline $1 / 5 / 2006$ & 26.9 & 6.1 & 10.3 & 35 & 0.9 & 16.5 & 0.12 & 1805 & 78.11 & 0.052 & 3.54 & 0.94 & $\rightarrow$ \\
\hline $1 / 6 / 2006$ & 26.3 & 6.0 & 10.4 & 42 & 0.8 & 16.2 & 0.12 & 1805 & 78.10 & 0.052 & 3.42 & 0.94 & $\rightarrow$ \\
\hline $1 / 7 / 2006$ & 26.2 & 5.9 & 10.4 & 39 & 1.0 & 16.1 & 0.12 & 1805 & 78.09 & 0.052 & 3.40 & 0.93 & $\rightarrow$ \\
\hline $1 / 8 / 2006$ & 26.5 & 6.0 & 9.4 & 40 & 1.1 & 16.3 & 0.12 & 1805 & 78.08 & 0.052 & 3.46 & 0.94 & $\rightarrow$ \\
\hline $1 / 9 / 2006$ & 26.7 & 6.6 & 10.1 & 39 & 1.1 & 16.7 & 0.12 & 1805 & 78.07 & 0.052 & 3.50 & 0.97 & $\rightarrow$ \\
\hline $1 / 10 / 2006$ & 28.4 & 8.4 & 8.4 & 40 & 0.7 & 18.4 & 0.13 & 1805 & 78.06 & 0.052 & 3.87 & 1.10 & $\rightarrow$ \\
\hline $1 / 11 / 2006$ & 28.3 & 8.6 & 9.6 & 46 & 1.0 & 18.5 & 0.13 & 1805 & 78.05 & 0.052 & 3.85 & 1.12 & $\rightarrow$ \\
\hline $1 / 12 / 2006$ & 30.0 & 9.4 & 7.7 & 37 & 1.0 & 19.7 & 0.14 & 1805 & 78.04 & 0.052 & 4.24 & 1.18 & $\rightarrow$ \\
\hline $1 / 13 / 2006$ & 27.0 & 10.0 & 9.8 & 46 & 0.9 & 18.5 & 0.13 & 1805 & 78.03 & 0.052 & 3.57 & 1.23 & $\rightarrow$ \\
\hline $1 / 14 / 2006$ & 27.0 & 8.3 & 10.0 & 45 & 1.1 & 17.7 & 0.13 & 1805 & 78.02 & 0.052 & 3.57 & 1.09 & $\rightarrow$ \\
\hline $1 / 15 / 2006$ & 26.9 & 10.6 & 10.1 & 44 & 0.9 & 18.8 & 0.14 & 1805 & 78.01 & 0.052 & 3.54 & 1.28 & $\rightarrow$ \\
\hline $1 / 16 / 2006$ & 27.6 & 6.2 & 10.2 & 55 & 1.1 & 16.9 & 0.12 & 1805 & 78.00 & 0.052 & 3.69 & 0.95 & $\rightarrow$ \\
\hline $1 / 17 / 2006$ & 28.0 & 8.5 & 10.5 & 56 & 1.1 & 18.3 & 0.13 & 1805 & 77.99 & 0.052 & 3.78 & 1.11 & $\rightarrow$ \\
\hline $1 / 18 / 2006$ & 27.9 & 8.3 & 10.6 & 51 & 0.9 & 18.1 & 0.13 & 1805 & 77.98 & 0.052 & 3.76 & 1.09 & $\rightarrow$ \\
\hline$\downarrow$ & $\downarrow$ & $\downarrow$ & $\downarrow$ & $\downarrow$ & $\downarrow$ & $\downarrow$ & $\downarrow$ & $\downarrow$ & $\downarrow$ & $\downarrow$ & $\downarrow$ & $\downarrow$ & \\
\hline
\end{tabular}

temperature $\left[{ }^{\circ} \mathrm{C}\right], \exp [.]$.2.7183 (base of natural logarithm) raised to the power [..].

Saturation vapor pressure as a function of air temperature, $e_{s}$

$$
e_{s}=\frac{e^{o}\left(T_{\max }\right)+e^{o}\left(T_{\min }\right)}{2}
$$

Soil heat flux $(G)$ :

$$
G_{\text {month }, i}=0.14\left(T_{\text {month }, i}-T_{\text {month }, i-1}\right)
$$

where $T_{\text {month }, i}$ mean air temperature of month $i\left[{ }^{\circ} \mathrm{C}\right]$ and $T_{\text {montt, }, i-1}$ mean air temperature of previous month $\left[{ }^{\circ} \mathrm{C}\right]$.

The psychrometric constant, $\gamma$, is given by:

$$
\gamma=\frac{c_{p} P}{\varepsilon \lambda}=0.665 \times 10^{-3} P
$$

where $\gamma$ psychrometric constant $\left[\mathrm{kPa}{ }^{\circ} \mathrm{C}^{-1}\right], P$ atmospheric pressure $[\mathrm{kPa}], \lambda$ 
latent heat of vaporization, $2.45\left[\mathrm{MJ} \mathrm{kg}^{-1}\right], c_{p}$ specific heat at constant pressure, $1.013 \times 10^{-3}\left[\mathrm{MJ} \mathrm{kg}^{-1}{ }^{\circ} \mathrm{C}^{-1}\right], \quad \varepsilon$ ratio molecular weight of water vapor/dry air = 0.622 .

The atmospheric pressure, $P$, is the pressure exerted by the weight of the earth's atmosphere. Evaporation at high altitudes is promoted due to low atmospheric pressure as expressed in the psychrometric constant. The effect is, however, small and in the calculation procedures, the average value for a location is sufficient. A simplification of the ideal gas law, assuming $20^{\circ} \mathrm{C}$ for a standard atmosphere, can be employed to calculate $P$ :

$$
P=101.3\left(\frac{293-0.0065 Z}{293}\right)^{5.26}
$$

where $P$ atmospheric pressure [kPa], and $Z$ elevation above sea level [m]

The net radiation $\left(R_{n}\right)$ is the difference between the incoming net shortwave radiation $\left(R_{n s}\right)$ and the outgoing net long wave radiation $\left(R_{n l}\right)$ :

$$
R_{n}=R_{n s}-R_{n l}
$$

where;

$$
R_{n s}=(1-\alpha) R_{s}
$$

where $R_{n s}$ net solar or shortwave radiation $\left[\mathrm{MJ} \mathrm{m}^{-2}\right.$ day $\left.^{-1}\right], \alpha$ albedo or canopy reflection coefficient, which is 0.23 for the hypothetical grass reference crop [dimensionless], $R_{s}$ the incoming solar radiation $\left[\mathrm{MJ} \mathrm{m}^{-2}\right.$ day $\left.^{-1}\right]$.

If the solar radiation, $R_{s}$ is not measured, it can be calculated with the Angstrom formula which relates solar radiation to extraterrestrial radiation and relative sunshine duration:

$$
R_{s}=\left(a_{s}+b_{s} \frac{n}{N}\right) R_{a}
$$

where $R_{s}$ solar or shortwave radiation [MJ m ${ }^{-2}$ day $^{-1}$ ], $n$ actual duration of sunshine [hour], $N$ maximum possible duration of sunshine or daylight hours [hour],

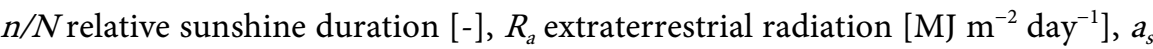
regression constant, expressing the fraction of extraterrestrial radiation reaching the earth on overcast days $(n=0), a_{s}+b_{s}$ fraction of extraterrestrial radiation reaching the earth on clear days $(n=N)$. If no actual solar radiation data are available and no calibration has been carried out for improved $a_{s}$ and $b_{s}$ parameters, the values $a_{s}=0.25$ and $b_{s}=0.50$ are recommended.

The daylight hours, $N$, are given by:

$$
N=\frac{24}{\pi} \omega_{s}
$$

where $\omega_{s}$ is the sunset hour angle in radians

$$
R_{a}=\frac{24 \times 60}{\pi} G_{s c} d_{r}\left[\omega_{s} \sin (\varphi) \sin (\delta)+\cos (\varphi) \cos (\delta) \sin \left(\omega_{s}\right)\right]
$$

where $R_{a}$ extraterrestrial radiation in the hour (or shorter) period [MJ m ${ }^{-2}$ hour $^{-1}$ ], $G_{s c}$ solar constant $=0.0820 \mathrm{MJ} \mathrm{m}^{-2} \mathrm{~min}^{-1}, d_{r}$ inverse relative distance Earth-Sun, 
$\delta$ solar declination $[\mathrm{rad}], \varphi$ latitude $[\mathrm{rad}], \omega_{s}$ sunset hour angle [rad].

$$
\left.\varphi[\text { Radians }]=\frac{\pi}{180} \text { [decimal degrees }\right]
$$

The inverse relative distance Earth-Sun, $d_{r}$, and the solar declination, $\delta$, are given by:

$$
\begin{gathered}
d_{r}=1+0.033 \cos \left(\frac{2 \pi}{365} J\right) \\
\delta=0.409 \sin \left(\frac{2 \pi}{365} J-1.39\right)
\end{gathered}
$$

\begin{tabular}{|c|c|c|c|c|c|c|c|c|c|c|}
\hline Date & FAO-PEN & PT & HAR & $\mathrm{TH}$ & BC & ENKU & PAN-P & PAN-A & PI-S & PI-ADAH \\
\hline $12 / 28 / 2005$ & 3.7 & 7.6 & 10.3 & 5.5 & 4.1 & 3.7 & 4.4 & 4.1 & 6.8 & 3.3 \\
\hline $12 / 29 / 2005$ & 3.5 & 8.8 & 10.4 & 4.7 & 3.9 & 3.4 & 4.3 & 4.4 & 8.7 & 7.1 \\
\hline $12 / 30 / 2005$ & 4.0 & 8.3 & 11.1 & 6.1 & 4.2 & 4.2 & 4.0 & 3.8 & 7.9 & 4.1 \\
\hline $12 / 31 / 2005$ & 3.7 & 7.7 & 10.4 & 5.4 & 4.1 & 3.6 & 4.3 & 4.0 & 9.0 & 4.5 \\
\hline $1 / 1 / 2006$ & 3.6 & 7.6 & 10.7 & 4.8 & 4.0 & 3.7 & 3.9 & 3.6 & 6.8 & 3.5 \\
\hline $1 / 2 / 2006$ & 3.6 & 7.8 & 10.6 & 4.7 & 4.0 & 3.6 & 3.7 & 3.5 & 7.7 & 4.2 \\
\hline $1 / 3 / 2006$ & 3.8 & 7.7 & 10.9 & 5.9 & 4.2 & 4.1 & 5.0 & 4.6 & 6.8 & 3.4 \\
\hline $1 / 4 / 2006$ & 3.7 & 7.7 & 10.9 & 5.1 & 4.1 & 3.9 & 4.8 & 4.4 & 7.9 & 4.0 \\
\hline $1 / 5 / 2006$ & 3.7 & 7.6 & 10.8 & 5.0 & 4.1 & 3.8 & 4.1 & 3.8 & 8.5 & 4.2 \\
\hline $1 / 6 / 2006$ & 3.5 & 7.8 & 10.6 & 4.9 & 4.0 & 3.6 & 3.9 & 3.7 & 6.9 & 3.9 \\
\hline $1 / 7 / 2006$ & 3.7 & 8.0 & 10.6 & 4.8 & 4.0 & 3.6 & 3.7 & 3.5 & 7.2 & 3.8 \\
\hline $1 / 8 / 2006$ & 3.7 & 7.9 & 10.7 & 4.5 & 4.0 & 3.7 & 4.2 & 4.0 & 7.5 & 4.1 \\
\hline $1 / 9 / 2006$ & 3.8 & 8.1 & 10.8 & 5.0 & 4.1 & 3.7 & 3.6 & 3.4 & 6.9 & 3.7 \\
\hline $1 / 10 / 2006$ & 3.4 & 6.9 & 11.3 & 5.0 & 4.3 & 4.4 & 5.6 & 5.1 & 6.2 & 3.4 \\
\hline $1 / 11 / 2006$ & 3.8 & 8.1 & 11.3 & 5.7 & 4.3 & 4.3 & 4.4 & 4.2 & 7.4 & 4.6 \\
\hline $1 / 12 / 2006$ & 3.7 & 7.1 & 11.9 & 5.2 & 4.4 & 5.0 & 3.6 & 3.3 & 8.4 & 4.3 \\
\hline $1 / 13 / 2006$ & 3.7 & 8.0 & 10.5 & 5.9 & 4.3 & 3.8 & 3.7 & 3.5 & 8.2 & 5.1 \\
\hline $1 / 14 / 2006$ & 3.8 & 8.3 & 10.8 & 5.5 & 4.2 & 3.8 & 4.1 & 4.0 & 7.1 & 4.3 \\
\hline $1 / 15 / 2006$ & 3.7 & 8.0 & 10.4 & 6.2 & 4.3 & 3.8 & 3.7 & 3.5 & 6.4 & 3.8 \\
\hline $1 / 16 / 2006$ & 3.7 & 8.9 & 11.3 & 5.2 & 4.1 & 4.1 & 4.0 & 4.0 & 7.2 & 5.4 \\
\hline $1 / 17 / 2006$ & 3.9 & 9.3 & 11.3 & 6.2 & 4.3 & 4.2 & 3.7 & 3.8 & 8.1 & 6.2 \\
\hline $1 / 18 / 2006$ & 3.8 & 8.7 & 11.3 & 6.1 & 4.2 & 4.2 & 4.4 & 4.3 & 7.1 & 4.9 \\
\hline$\square \downarrow$ & $\downarrow$ & $\downarrow$ & $\downarrow$ & $\downarrow$ & $\downarrow$ & $\downarrow$ & $\downarrow$ & $\downarrow$ & $\downarrow$ & $\downarrow$ \\
\hline
\end{tabular}

Table S2. Results overview of potential evaporation methods between 2005 and 2015 for Bahir Dar meteorological station. Abbreviations of the reference evaporation methods are explained Figure 1. 
where; $J$ is the number of the day in the year between 1 ( 1 January) and 365 or 366 (31 December). The sunset hour angle, $\omega_{s}$, is given by:

$$
\omega_{s}=\arccos [-\tan (\varphi) \tan (\delta)]
$$

Net long wave radiation $\left(R_{n l}\right)$ :

$$
R_{n l}=\sigma\left[\frac{T_{\mathrm{max}, \mathrm{K}}^{4}+T_{\mathrm{min}, \mathrm{K}}^{4}}{2}\right]\left(0.34-0.14 \sqrt{e_{a}}\right)\left(1.35 \frac{R_{\mathrm{s}}}{R_{\mathrm{so}}}-0.35\right)
$$

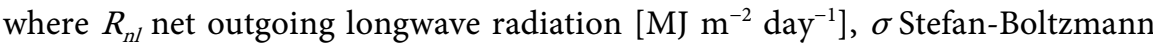
constant $\left[4.903 \times 10^{-9} \mathrm{MJ} \mathrm{K}^{-4} \mathrm{~m}^{-2}\right.$ day $\left.^{-1}\right], T_{\max , \mathrm{K}}$ maximum absolute temperature during the 24-hour period $\left[\mathrm{K}={ }^{\circ} \mathrm{C}+273.16\right], T_{\min , \mathrm{K}}$ minimum absolute temperature during the 24 -hour period $\left[\mathrm{K}={ }^{\circ} \mathrm{C}+273.16\right], e_{a}$ actual vapour pressure [kPa], $R_{s} / R_{s o}$ relative shortwave radiation (limited to $\leq 1.0$ ), $R_{s}$ measured or calculated solar radiation $\left[\mathrm{MJ} \mathrm{m}^{-2} \mathrm{day}^{-1}\right], R_{s o}$ calculated clear-sky radiation $\left[\mathrm{MJ} \mathrm{m}^{-2}\right.$ day $\left.^{-1}\right]$.

$$
R_{\text {so }}=\left(0.75+2 \times 10^{-5} Z\right) R_{a}
$$

where; $Z$ station elevation above sea level [m].

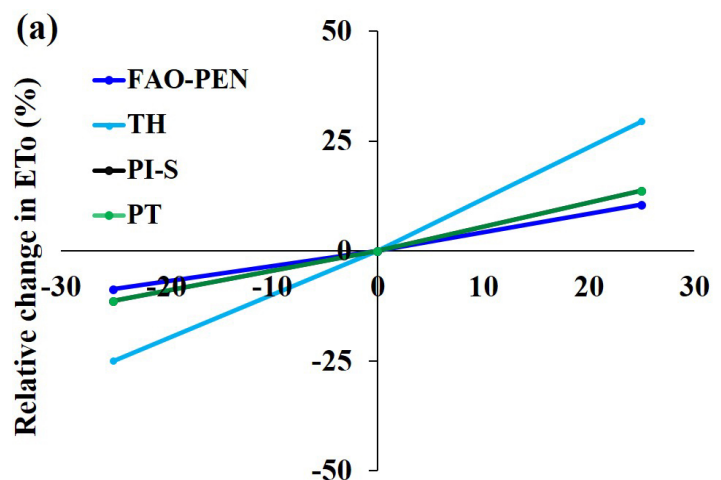

Relative change in temperature $(\%)$

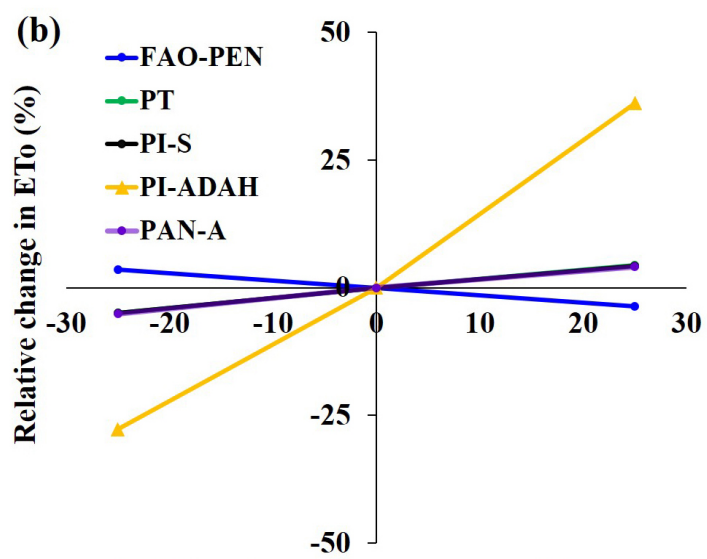

Relative change in temperature $(\%)$

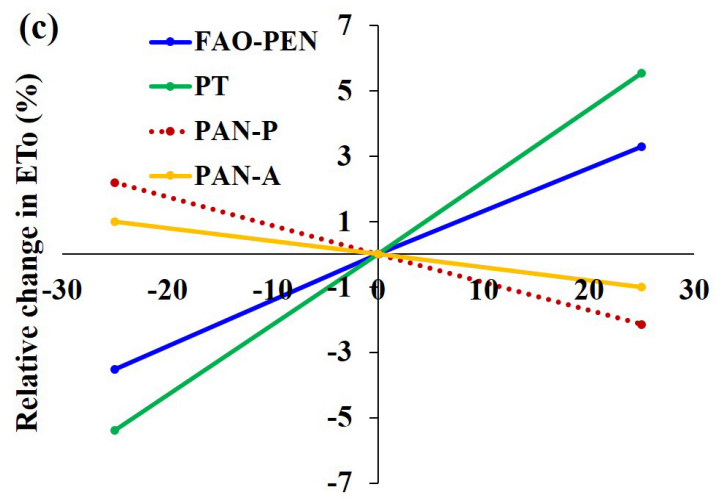

Relative change in temperature (\%)

Figure S2. Relative change in reference potential evaporation of Bahir Dar station for the change of sunshine hour (a), relative humidity (b) and wind speed (c) between the year 2005 and 2015. Abbreviations of the reference evaporation methods are explained Figure 1. 

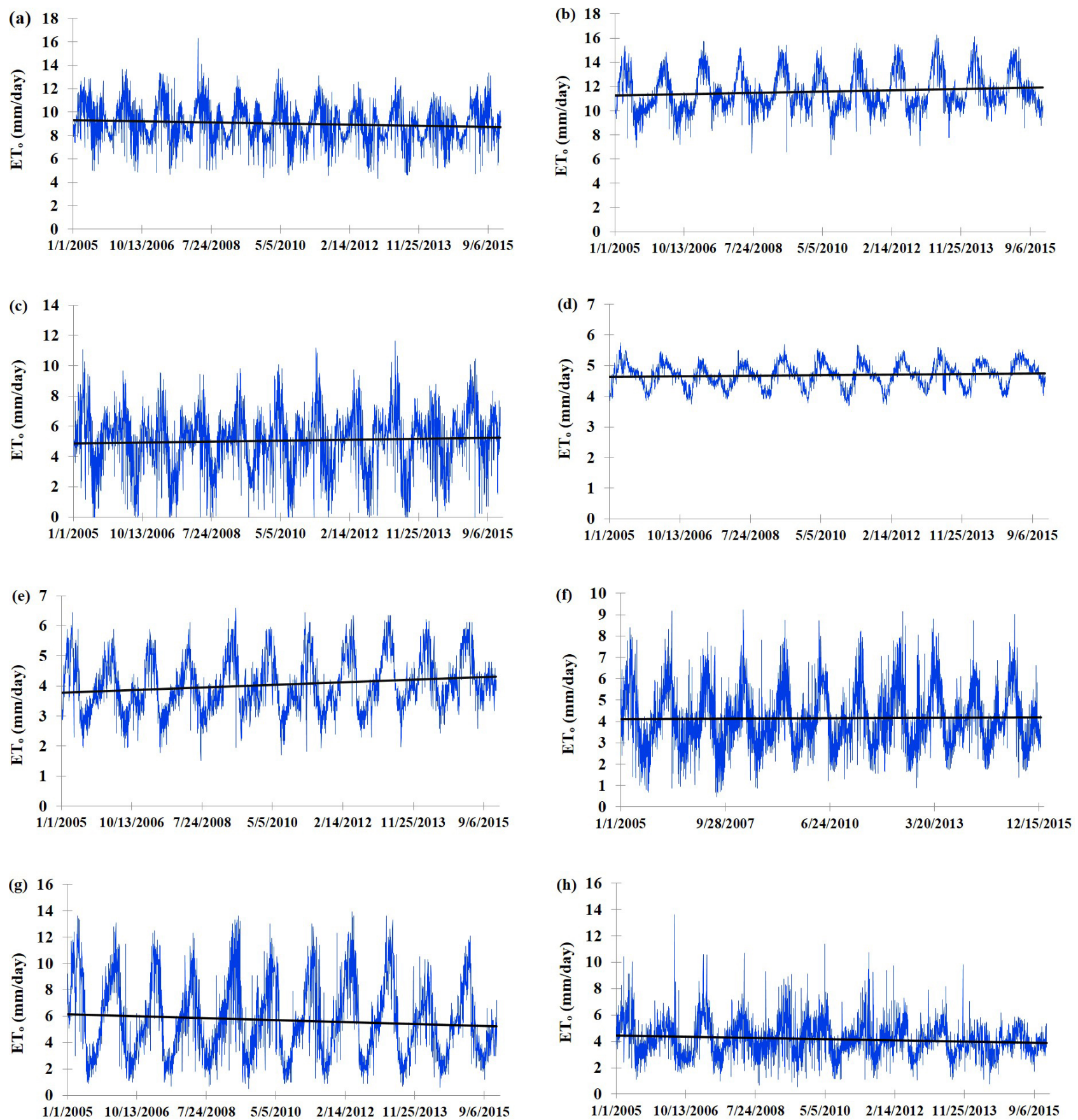

Figure S3. Daily time series plots of $\mathrm{ET}_{0}$ for (a) Priestley \& Taylor; (b) Hargraves; (c) Blaney-Criddle; (d) Enku; (e) Pan-Allen; (f) Piche-Stanhill; and (g) Piche-Adam and Ahmed. 